\title{
Art \& Technology: a Maker Space Experiment for Children
}

\author{
Greg Giannis
}

\section{Victoria University}

\begin{abstract}
What can primary school children learn from the simple task of dismantling everyday electronics in an informal maker space environment? Can this type of activity be utilized to engage children in STEM related learning? Can what practitioners in the art/science nexus have learnt over many years be leveraged to enhance student engagement in STEM activities? This paper is a report on a simple experiment and its outcomes conducted in a trial maker space at a Melbourne primary school.
\end{abstract}

\section{Keywords}

STEAM, play, child-centric, creativity, art, technology 
Over the last 15 years I have been teaching digital technologies to students from the creative arts fields. This has presented many challenges and I have come against a great deal of resistance, more so from art students than any other student body. I persist as it reflects my own philosophy and practice. I believe that there is an imperative to engage with contemporary technologies as they have come to play such a dominant role in our lives. Or as Douglas Rushkoff put it in relation to software, 'Program or be Programmed' (Rushkoff 2011).

The creative arts fields covers areas such as Visual Arts, Graphic Design and Digital Media. Students tend to be visual learners and communicators, and have a resistance to anything related to the hard sciences which computer software and hardware is perceived to be part of. This presents a problem and missed opportunity for artists to be engaged with a medium that is so prevalent in our society, or as Geert Lovink puts it:

"We need input from critical humanities and social science that starts a dialogue with computer science on an equal basis.... The submissive attitude towards the hard sciences and industries in arts and humanities needs to come to a close". (Lovink 2014)

\section{Fellowship}

In 2015, I undertook an International Fellowship that allowed me to visit experts and centers of excellence involved in the teaching of technology to students in the creative arts fields. I visited many places and spoke to some very inspiring people including Casey Reas from UCLA, Kylie Peppler from UI and Dan Sullivan from NYU. Upon my return, I set about disseminating the information I had procured through my research.

I ran many professional learning sessions for teachers and started teaching into Masters of Education course. With the arrival of the new Digital Literacies curriculum in Australia, there was a strong demand for professional learning from the Primary and High School sectors. I felt that the best means to support these teachers (and the students and parents) was through a maker space focusing on creativity as a means to better engage

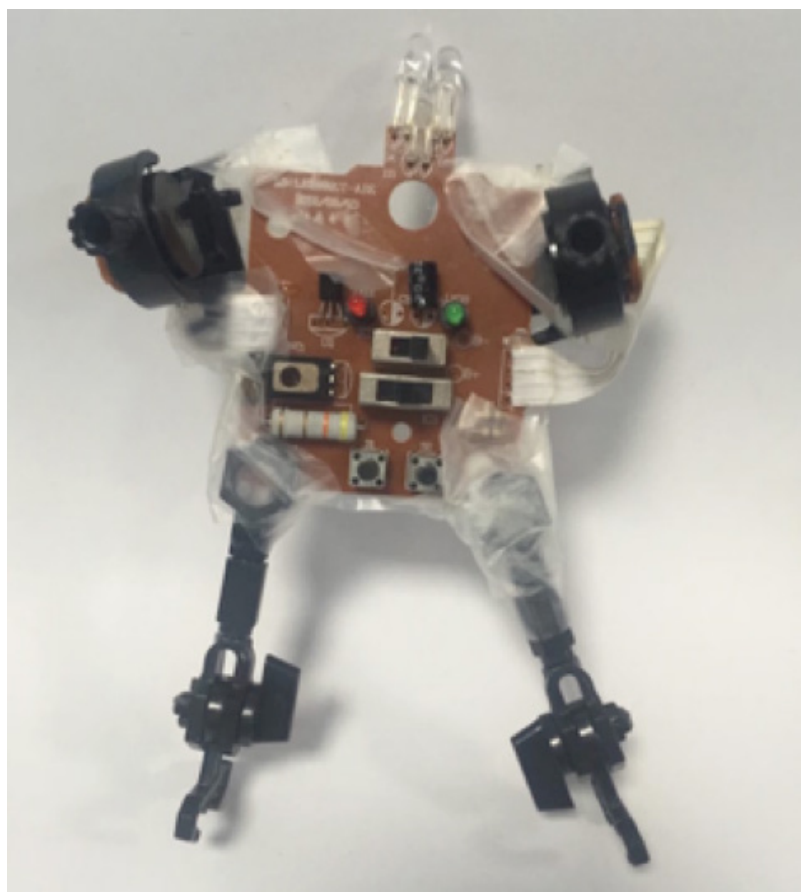

Figure 1 
students in STEM activities. This would provide an on-going resource for the community, which would have the potential for greater impact than any short-term learning sessions. In summary, I set about to investigate the teaching of digital skills to creative arts students, and in the process developed expertise in the teaching of STEM through the arts, i.e. now commonly referred to as STEAM.

\section{Intent of Maker Space}

The maker space project was run over a semester in 2016, with primary school children, parents and volunteers. The maker space itself was created with limited funds and as a trial to test the potential for engagement and learning. Various activities were prepared for the attendants: drawbots, paper circuits, paper craft, scratch, etc., activities that would be familiar to anyone that has delved into maker spaces and the types of activities offered. But the activity that captured the imagination and attention of all participants was the project described here. Not a project that I have found documented elsewhere, but one that is simple, easily duplicated, requires very few resources and is very engaging. It was also offered to teachers during a professional learning session, and the feedback from their own trials was outstanding.

\section{The Experiment}

The community was asked to donate any broken and unused electronics, including computers, mobile phones and toys. Simple tools: screwdrivers, pliers, cutters were already available and a space was generously provided by the principal. Dusty items accumulated as donations arrived from the community, giving us a range of materials to work with. The project was allowed to grow with little intervention from the facilitators apart from ensuring the safe use of tools, explanations of simple electronics and the occasional assistance required when disassembly seemed impossible. This was an intentional strategy and based on research, prior experiences and let's say 'a gut feeling'.

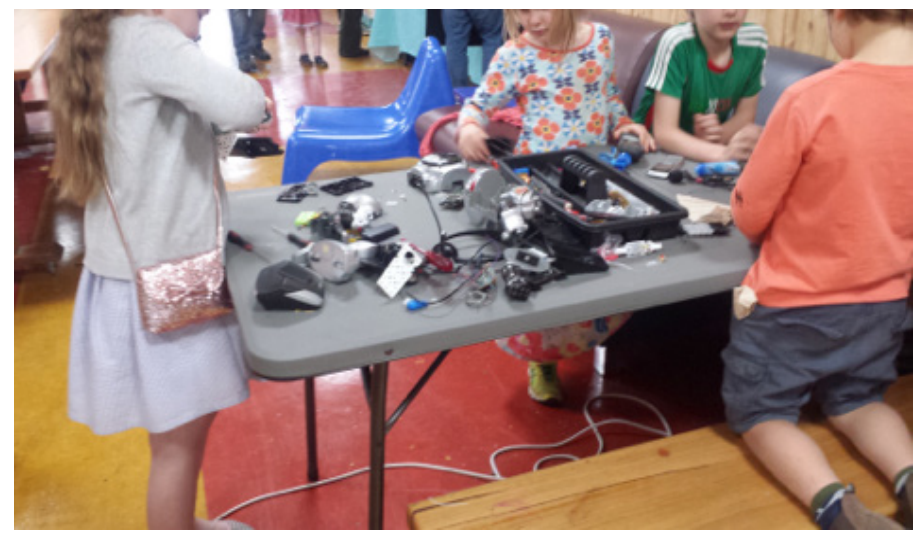

Figure 2

Initially, the fascination for the children was the unrestricted allowance to disassemble familiar electronics. What did these black boxes of technology contain that enabled them to do such miraculous things? How did an LED work, and why did the motor spin when connected to a battery? The joy expressed by the children in their ability to make an LED light or a motor spin was palpable. It was clear that a great deal of learning was taking place guided by the children's curiosity, creativity and sense of experimentation.

The potential for further learning was apparent. Children are reading the world in ways that don't necessarily involve reading printed texts or even screens. With an older 
cohort we could look at the materials involved in the production of the familiar devices, their origins, scarcity, the production processes involved, conditions of labor, environmental impact, waste, consumerism and so on. The space was created with the intention of also supporting the school's teachers; helping them to create engaging, creative experiences for the students, in order to address the digital literacies curriculum recently imposed on the education sector in Australia.

After many sessions of disassembly, parents set about sorting the salvaged materials creating an inventory of salvaged bits and pieces: motors, LED's, gears, tiny screens, assortment of plastics, wires, screws, assorted plugs and connectors, etc. It was very helpful to have the support of parents on hand, often enjoying the activity as much if not more than the children themselves. But this seemed to me an excellent way for parents to support and involve themselves in their children's learning. Furthermore, for many parents it may be the first engagement with electronics and media devices in ways beyond simply using them.

\section{Creativity}

With very little provocation and access to glue guns, many of the students set about creating small sculptures from the salvaged materials. Many seemed to resemble tiny robots, as the aesthetic aspects of the salvaged materials lent themselves well to this reconfiguration in the minds of the children.

Others followed suit, whilst some totally surprised me with their creations. For example, a standout was a percussion machine (see Figure 3). When the battery was connected the fan rotated and a small metallic segment was made to contact with the fan blades producing a percussive effect. This student had taken the idea well beyond any that the others students and adults had.

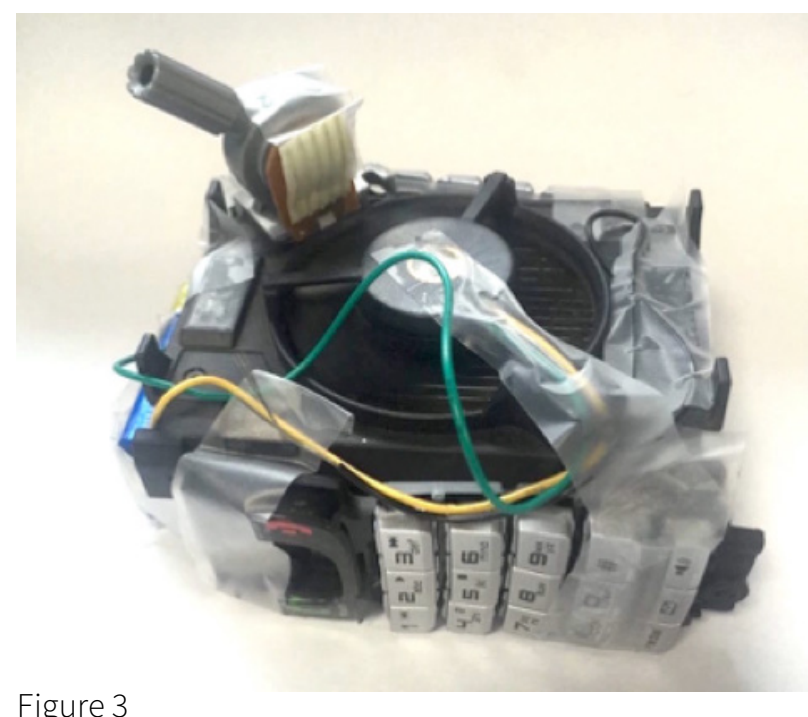

Figure 3

I wondered if the same learning could have been achieved without this hands-on approach. More than likely not, as the attraction was the doing, and the learning came as a result of this. It was working with objects that provided the motivation, in ways that words can't. These objects did take on a life of their own, initiated action, and could be easily understood. This approach to learning, Constructionism, has been championed by Seymour Papert, a student of Piaget whom had coined the term Constructivism. This pedagogical 
approach is gaining significant attention given the rise of maker spaces. Other pedagogical inspiration comes from the Reggio Emilia philosophy (Reggio Emilia Approach 2016).

Collaborative play was an important element in the processes described above. With fewer restrictions and the time to play, a recognized prerequisite for creativity, the children collaborated in order to assist one another and share proudly, their own newly acquired expertise. The importance of play cannot be under-estimated. Many studies and reports highlight the importance-'play creates learning moments.' For example, there were no expectations or prescribed outcomes and this seemed liberating for the children: 'In play it is as though [the child] were a head taller than himself ... play contains all developmental tendencies in a condensed form and is itself a major source of development' (Vygotsky 1978).

The children also formed powerful emotional attachments to their projects, carefully dissecting toys so as not to damage a 'cute' toy's exterior, securely storing work in progress so that they could continue the following week, handling their creations with care so as not to damage the often fragile creations.

I must also mention that in a very few instances there was a tendency by some children to want to destroy an item in a rough and dangerous way. In one session, I looked around to see a group of boys standing back from a table, all wearing safety goggles, whilst one was poised with hammer in hand, ready to bear down on an old mobile phone. I suggested that unless the student was able to explain to me what could be learned from simply smashing the phone, then I could not allow it as it was too dangerous and one of the important aspects of working in this space was taking care of one another. The student could not come up with a valid reason to dismantle the phone using this method so the method was abandoned.

Gender differences also became irrelevant in this space. Interest and level of engagement did not seem to depend upon gender. I could only surmise that this generation of students had not been exposed to the biases of former generations where male and female students were encouraged to take up interests deemed suited to their gender. The school itself had not instilled or supported this false notion, as should be the case.

I felt that it was important to document the maker space trial. I utilized a blog to capture the experiment: (http://blog.facade.net.au). This has become an invaluable resource for the dissemination of the maker space activities.

On a closing note, it was important to receive feedback from parents. Parents expressed their enthusiasm for the initiative, participated with their children and provided invaluable assistance in the way of resources, advice, assistance in applying for sponsorship and so on. The mother of a regular attendant remarked that the maker space was the highlight of her son's week, which is something educators need to take note of.

\section{References}

Rushkoff, D 2011, Program or Be Programmed: Ten Commands for a Digital Age, Soft Skull Press, Berkeley

Lovink, G 2014, 'What is the Social in Social Media?', in Art in the Global Present, Papastergiadis \& Lynn (eds.) http://epress.lib.uts.edu.au/books/art-global-present p107

Reggio Emilia Approach 2016, Retrieved December 23, 2016 from http://www.reggiochildren.it/identita/reggio-emilia-approach/?lang=en

Vygotsky, L 1978, 'The Role of Play in Development', in Mind in Society (Trans. M. Cole), Harvard University Press, Cambridge, MA, pp. 92-104 